\title{
Lost in the Mail: A Field Experiment on Crime
}

\author{
Marco Castillo ${ }^{\mathrm{a}, *}$, Ragan Petrie ${ }^{\mathrm{b}}$, Maximo Torero $^{\mathrm{c}}$, Angelino Viceisza $^{\mathrm{c}}$ \\ a School of Public Policy, Georgia Institute of Technology, Atlanta, GA 30332, USA \\ b Department of Economics, Georgia State University, Atlanta, GA 30303, USA \\ c International Food Policy Research Institute, Washington, DC 20006, USA
}

January 2009

\begin{abstract}
Crime in the mail sector can hamper the development of electronic markets. We use a field experiment to detect crime and measure its differential impacts. We subtly, and realistically, manipulate the content and information available in mail sent to households and detect high levels of shirking and stealing. Eighteen percent of the mail never arrived at its destination, and even more was lost if there was even a slight hint of something additional inside the envelope. Our study demonstrates that privatization has been unable to extricate moral hazard and that crime is strategic and not equally distributed across the population.
\end{abstract}

\footnotetext{
* This work was completed while Castillo and Petrie were on leave at the Interdisciplinary Center for Economic Science (ICES) at George Mason University. We are grateful to Dan Houser and the Mercatus Center for their hospitality. We thank David Solis for conducting the follow-up survey and Cesar Ciudad for coordinating the mail recipients. Seminar participants at ICES, Georgia Institute of Technology, Virginia Commonwealth University, the World Bank, the Workshop on Economics Experiments in Developing Countries at CIRANO in Montreal, and the 2007 North American Economic Science Association Meetings in Tucson gave helpful comments.
} 


\section{Introduction}

An important condition for markets to develop and thrive is to have an efficient system for transporting goods and services. Without this, transaction costs may be too high to support some markets, and only consumers with sufficient means may be able to participate. To expand the breadth and depth of markets, including electronic trade, a well-functioning, low-cost mail delivery system is needed. Inefficiency and crime in the system can hinder markets from developing, as well as prospering.

In many developing countries, corrupt behavior in the provision of public services is not only widespread but can create important inefficiencies and inequities (Bertrand, Djankov, Hanna, Mullainathan, 2007; Hunt and Laszlo, 2008; Reinikka and Svensson, 2005). In an environment where the provision of public services is privatized, it is not clear if such behavior is lessened or not. In this paper, we show that in the presence of moral hazard, even private firms providing public services, such as mail delivery, can face a significant level of corrupt and strategic behavior. Importantly, we show that this has equity consequences. The cost of crime is not equally shared by all citizens - the middle class suffers the most.

Indeed, theory and casual observation would suggest that people may be affected differentially by crime and that crime may be strategic. Becker (1968) theoretically shows that neither the participation in illegal activities nor the diseconomies caused by criminal activities are expected to be uniformly distributed across the population. Also, several authors have provided evidence that the social and private benefits and costs associated with committing a crime are important to determine its incidence. ${ }^{1}$ Deterrence, the risk of being caught, and social norms all seem to be important factors in

\footnotetext{
${ }^{1}$ For examples of empirical and experimental work, see See Erlich (1973), Levitt (1997), Duggan and Levitt (2002), Glaeser, Scheinkman and Sacerdote (1996), Jacob and Lefgren (2003), Di Tella and Schargrodsky (2003, 2004), Olken (2007), Fisman and Miguel (2007), Reinikka and Svensson (2004) and Armantier and Boly (2008), among others.
} 
deciding whether to commit a crime or not.

We use a unique field experiment that allows us to develop a behavioral measure of crime. The design measures which segments of the population are more likely to suffer from crime and whether this conforms with economic rationality broadly understood. Our study concentrates on the delivery of mail, and we do so for several reasons. First, the existence of a reliable mail sector is considered to be instrumental in the growth of electronic trade (World Bank, 2009). Second, mail services are widely used by all segments of the population. Third, as we will describe, mail delivery is amenable to field experimentation with little or no intrusion. Fourth, mail delivery is a highly decentralized activity likely to suffer from moral hazard problems regardless of ownership. For instance, sources of lost non-certified mail are nearly impossible to detect. Finally, crime in the mail sector is expected to be highly correlated with the expected gains and losses of committing a crime and much less with social pathologies. That is, it is a crime of opportunity that can allow us to understand the economic motivation behind crime.

We develop a novel and simple empirical strategy to measure the probability that a piece of mail arrives at its destination. We send identical envelopes to different households in Lima, Peru from two American cities and record arrivals. The experiment includes a large population of volunteer households across neighborhoods of different socio-economic backgrounds. To better understand the motivation behind the commission of crime, we manipulated the contents, the sender of the mail and the gender of the recipient. In particular, every household was sent four envelopes over the course of a year. Two envelopes had a sender with a foreign name and two had the last name of the sender and recipient matched. Finally, one of each of the two envelopes contained something inside the enclosed card (a small amount of money) that could not be easily detected without careful attention. The other envelope just contained the enclosed card. All these modifications were as subtle as possible and the order in which each different envelope was sent was random. 
By manipulating the information made available to the person handling the mail, our design allows us to test several hypothesis behind the commission of crime. First, mail can be lost because the cost of delivery is larger than the cost of being caught shirking. Lost mail might be a reflection of apathy rather than crime. Therefore, comparing rates of lost mail containing money with those not containing money permits us to detect if crime is taking place. Second, if those handling mail behave strategically, one would expect that they will make use of information on the social distance between the recipient and the sender and the characteristics of the recipient. Therefore, comparing similar pieces of mail across subgroups can potentially reveal the expectations of those handling the mail. For instance, if a letter from a family member is more likely to contain something of value (i.e. money), then letters from family members would be lost at a higher rate.

The experiments show first that the mail service in Peru is highly inefficient. The overall rate of mail lost is $18 \% .^{2}$ The loss rate, however, hides the fact that mail containing money is lost $21 \%$ of the time while mail containing no money is lost $15 \%$ of the time. That is, we find evidence of shirking as well as crime. Also, the quality of service is not independent of socioeconomic status. Mail is lost at the same rate (roughly 18\%), whether it contains money or not, when sent to a poor neighborhood. When sent to a rich neighborhood, however, mail without money is lost only $10 \%$ of the time and mail with money is lost $17 \%$ of the time. This suggests loss is happening within Peru rather than the U.S. We confirm that given the geographical distribution of post offices, this cannot be attributed to a lack of manpower.

Our approach has several advantages. By randomly assigning treatments to different populations, it provides the necessary counterfactuals to test the presence of strategic behavior. The study also avoids potential biases due

\footnotetext{
${ }^{2}$ Compared to the less than $0.5 \%$ of mail reported lost in the U.S. or the U.K., this is very large. Note that loss rates in the U.S. and the U.K. are for reported mail lost. This will underestimate the problem if not all mail lost is reported. Our experimental measure is for all mail lost that should have arrived at a destination.
} 
to experimenter effects by using an existing service that likely suffers from moral hazard problems. By using a widely used service and careful selection of the sample, our study overcomes the criticisms of lack of external validity. Finally, our study provides a behavioral measure of crime that avoids common measurement problems and underreporting.

Our research makes several contributions. First, it shows that there still remains high barriers to expand commerce that relies on the mail sector to transport goods and services. Second, it speaks to the problems that developing countries face when trying to solve inefficiencies through privatization of public services. Private firms suffer the same asymmetric information that governments do. The fact that subtle changes in the characteristics of envelopes generate adjustments in behavior suggests that mechanisms based on random checks (Becker and Stigler, 1976) might be too difficult or costly to implement. Third, our research presents new evidence that crime is not shared equally. The middle class is taxed more heavily. Finally, our research shows that crime is strategic and depends on expectations and the probability of being caught.

The paper is organized as follows. The next section presents our hypotheses on crime. Section 3 presents a description of the Peruvian postal system. Section 4 presents the experimental design and Section 5 the results. In Section 6, we run robustness checks, and Section 7 concludes.

\section{Hypotheses on Crime}

Our experiment allows us to look at crime in equilibrium. By varying the content and information available on each piece of mail, we can better understand the strategy of crime and who suffers the most from crime. Below we present some hypotheses on how our manipulations will affect mail loss.

We posit that the incidence of crime in equilibrium is a function of the probability of being caught stealing and the probability that the victim has 
something of value to steal. ${ }^{3}$ In the context of the mail sector, this implies that mail loss will be a function of the probability that the postal worker will be fired or punished if caught stealing mail and the probability, or the expectation, that the sender of a piece of mail includes something of value.

Specifically, we would expect that mail loss will decline as the probability of being caught stealing increases and as the probability that mail is valuable decreases. So, as it becomes easier to identify the person responsible for mail loss, because of monitoring on the side of the firm or complaints on the side of the customer, mail loss should decline. Also, as the piece of mail signals that it might contain something of value, mail loss should increase.

In our experiment, we manipulate information that we expect to affect these probabilities and record mail loss. For example, by making the envelope slightly thicker with something inserted inside, we expect mail loss to increase as postal workers may suspect there is something of value. Also, by decreasing the social distance between the sender and the recipient, such as having the sender be a family member, we expect mail loss to increase. By sending mail to different neighborhoods, we can see if mail loss decreases in wealthier neighborhoods, relative to poorer neighborhoods, because we would expect that the rich are more likely to complain if mail does not arrive. The effects, however, may be nonlinear. While we expect service to be better as neighborhood income rises, this will interact with the expectation that recipients have something of value to send. People who live in wealthier neighborhoods may be more likely to have something of value to send, but they may also be more likely to pay a higher price for more secure services.

\footnotetext{
${ }^{3}$ Becker (1968) and Erlich (1973) present detailed models of decision making by individuals considering committing a crime. The interaction between a mailman and a customer can be thought of as a zero-sum game. If a person sends valuables with probability one and there is moral hazard, mail will be certainly stolen. If the mailman never steals, a customer might feel safe sending valuables in the mail. In equilibrium, one would expect that those customers that have a larger marginal benefit of using the mail to send valuables will face a larger average level of crime. Hypotheses on the effects of costs, benefits and the probability of detection on crime can be derived from a standard principal-agent model where wages are a function of unobservable effort on the part of the mailman.
} 
Recipients in poor neighborhoods may not be expected to receive anything of value, so mailmen may not bother to look carefully.

In sum, we expect mail loss to increase as the probability of being caught stealing declines and the probability of valuables increases. The relationship across neighborhoods may be nonlinear because the probability that something of value is being sent will depend on the recipient's likelihood of receiving something of value and the likelihood that the recipient has alternative means for receiving valuables.

\section{Mail in Peru}

We look at the incidence and nature of lost mail sent from the U.S. to Peru. To better understand how and where crime may be happening, below we briefly describe the Peruvian postal system and how mail is delivered.

The postal system in Peru is a private concession of the Peruvian government and was privatized in 1991. The company does not have exclusive rights to deliver letters, as is the case in the U.S., but practically speaking, they are the only provider of low-cost, non-package mail service in Peru. There are alternative means for sending mail, including certified services offered by the post office, but they are very expensive, costing about 100-200\% more depending on the destination.

Mail sent from overseas arrives in Peru at a central processing facility located in the capital city Lima. The facility sorts all mail, domestic and international, and sends it to large district or regional administration offices in Lima or other regions in Peru for further sorting and delivery. There are also small post office branches where further sorting of mail for delivery may occur. Some branches offer mail pick-up services as well. There are nine administration offices in Lima with an average of 72 employees per office, and there are 39 branches with an average of 2.5 employees per branch. The administration offices employ mail workers, mail carriers, and management. The post office branches employ workers and carriers. Mail carriers are paid 
a fixed salary, slightly higher than the minimum wage, and many have steady employment.

The mail sector in Peru was privatized with the goal of making it more efficient. It is also a monopoly provider of low-cost mail service, which could make it less efficient. And, it is a decentralized system, with mail sorting occurring at various places, which makes it difficult to monitor. These characteristics make an ideal environment to examine strategic behavior and crime.

\section{Experimental Design}

The experiment provides a behavioral measure of crime. We send envelopes from the United States to Peru through the normal mail services in both countries (U.S. Postal Service and the Peruvian postal service, respectively). We use a list of residential addresses in metropolitan Lima, Peru that are geographically representative of poor, middle, and high income neighborhoods. A resident of each address is the recipient of the envelope and reports to us if the envelope arrives or not.

The $2 \times 2$ design we employ varies the contents of the envelope and the sender's name. The contents of the envelope is a card and either two $\$ 1$ bills folded in half or no money. The sender's name is either a foreign name (i.e. J. Tucker, M. Scott) or the same family name as the recipient (i.e. M. Sosa, L. Cordova). ${ }^{4}$ Varying the sender's name allows us to test if names signal that something of value is in the envelope (i.e. money). The design is outlined in Table 1 and includes the number of envelopes sent in each treatment.

To get a valid estimate of crime, it is important that the envelope look realistic and like something that would normally be sent in the mail. So, we chose an opaque solid-colored envelope and card (of the same color). The

\footnotetext{
${ }^{4}$ In South America, including Peru, everyone has two last names. The first is the last name from the father and the second is the last name of the mother. We use the first last name.
} 
envelope looks like one that would be sent for a birthday or other special occasion. Keeping with that idea, on the inside of each card, we handwrite "Happy Birthday" or "Feliz Cumpleaños" - depending on the return addressee's name - and sign Josh or Mike or Marco or Luis. We do this because if the card is stolen or opened, we want it to appear, to the mailman, like it was actually sent by the person whose name appears on the front of the card. Figure 1 gives examples of two of the envelopes that were sent to the same address in the course of the study. To preserve confidentiality, we have blacked out the addresses of the sender and recipient and the recipient's first name. The first envelope gives an example of mail sent by a foreigner to a recipient and the second envelope gives an example of mail from a family member to a recipient.

Because the envelope is opaque, the greeting inside the card cannot be seen. If the card contains money, this also cannot be seen, even if held up to the light. One can, however, feel that there is something in the envelope because the folded two $\$ 1$ bills make a very subtle bump. It is impossible to determine what exactly is in the envelope. ${ }^{5}$ But, there is a hint that the envelope contains something other than the card. We chose this subtle manipulation so that anyone looking for something to steal would need to pay careful attention for signs that the envelope contained something that might be worth stealing.

All envelopes have handwritten addresses, stamps for postage and an airmail stamp on the front of the envelope. There are two return addresses in Atlanta and two in Washington, DC. All addresses are real so that we could monitor if the card was returned to the U.S. for any reason. The envelopes are glued shut, making it difficult to steam open, reseal and deliver. Envelopes are always mailed from one of two locations. Envelopes with a return address

\footnotetext{
${ }^{5}$ We could very well have placed folded pieces of paper in the envelope instead of money, but we want the envelopes and contents to be realistic, especially in case the envelope was lost or stolen. This is in line with the long-held tradition in experimental economics of avoiding subject deception.
} 
from Atlanta were mailed from the main post office in downtown Atlanta, and envelopes with a return address of Washington DC were mailed from a post office mailbox in Washington DC. The color of the envelope, the return address and the handwriting on the envelope are randomized across the four treatments. ${ }^{6}$ Envelopes were sent during the period November 2006 - November 2007.

Mailboxes in Peru are secure and not exposed to theft from people passing by on the street. Typically mail is placed in a locked mail box inside a locked gate or entryway. Or, it is placed under the door of the locked residence. Mail is not left in post boxes on the streets, as is the case in the U.S.

To find recipient addresses, we tapped into two networks of people who engage in research to recruit volunteers willing to receive the cards and report to us. ${ }^{7}$ The two networks include people from a variety of demographic and income groups. The important design element for us was that the addresses where the mail was sent were geographically diverse. So, even though the mail recipients might know one another, the addresses are disperse across locations. To minimize the number of addresses in the study for any given post office, no more than four households were within a 1-kilometer radius of each other (i.e. 0.62 miles or the equivalent of ten blocks). We mapped all the recipient addresses using GIS to minimize agglomeration and also to verify that the addresses were correct and active. This ensures that non-arrival of mail is not due to an incorrect address.

Recipients of the mail reported the arrival or non-arrival of each envelope and kept any money if an envelope with money arrived. They were instructed to not ask the mailman about the card or go to the post office to enquire. After the envelope was put in the mail in the U.S., we sent an e-mail to the recipients telling them that an envelope was sent. They were instructed to inform us when it arrived, who is was from, the color, and the contents.

\footnotetext{
${ }^{6}$ We did this to insure that each envelope sent to a household by a different person was indeed handwritten by a different person.

${ }^{7}$ We opted for this method to ensure honest reporting.
} 
They were not told ahead of time the characteristics of the envelope or if the envelope contained money. This was done to ensure no a priori bias in reporting.

To compensate recipients for their time and help, at the end of the experiment, we conducted a lottery with cash prizes for recipients who reported. Recipients knew of the lottery before we began sending envelopes. To verify mail receipt responses, in December 2007, we conducted a follow-up survey to responses and collect more individual data on mail recipients. This also allowed us to verify for a second time that addresses were correct. All addresses were verified, and all previous responses were confirmed. This gives us confidence that our data are accurate. ${ }^{8}$

\section{Results}

We would like to know the patterns of mail loss geographically, across various demographic characteristics and across our treatments. We first turn to a description of the sample, then main findings, evidence of strategic crime and finally robustness checks.

\subsection{Sample Selection}

Table 2 shows descriptive statistics on the individual and geographical characteristics of the mail recipients. The sample is split roughly half and half between male and female recipients. The distribution of residents across low, middle and high-income neighborhoods is not evenly distribution, with more people living in middle-income neighborhoods. ${ }^{9}$ Most recipients have

\footnotetext{
${ }^{8}$ We asked the recipient if they received an envelope during a certain period of time and asked the recipient to report the return address and color of the envelope. Recipients were able to correctly confirm reports from 4-5 months earlier.

${ }^{9}$ Low-income neighborhoods are ones where the percent of the population considered poor is $30 \%$ or higher. Middle-income neighborhoods are those where the percentage is between 10-30\%, and high-income neighborhoods are those where the percentage is less than $10 \%$. We show later that our results are robust to other definitions of economic
} 
a university education, are married or living with their partner and have a family member that lives in the United States. This latter result is important as it makes receipt of a card from the United States not seem strange and also attests to the degree of mail that could potentially come from the United States. Recipients have lived in their current residence for an average of 16.5 years, and the nearest post office is three minutes away.

An important component of our experimental design, in addition to a diverse and representative distribution of individual mail recipient characteristics, is that the distribution of recipient addresses is geographically disperse across neighborhoods and post offices and is representative of metropolitan Lima. Figure 2 shows the geographical distribution of residents in our study. The residents cover the majority of the city. There are fewer residents in some of the peri-urban areas of the city, but the addresses are nicely distributed across neighborhoods. This gives us observations across most areas of Lima and confidence that our results apply to the larger, city-wide mail sector.

\subsection{Main Findings}

Turning to loss rates, we see that mail service in Lima is inefficient and subject to crime. Table 3 shows loss rates overall and by income groups. Overall, $18 \%$ of all envelopes sent through the mail never arrived at their destination. Envelopes with money were less likely to arrive than envelopes without money, so it does not appear that mail loss is solely due to bad service. This hints more of criminal activity. Over $21 \%$ of envelopes with money did not arrive, whereas $14.8 \%$ of envelopes without money did not arrive. This $50 \%$ increase in loss is statistically significant (one-side p-value $=0.023$ ).

How was mail lost across our four treatments? The bottom panel of

status. The proportion of people living in poverty is from the latest poverty map (2006) calculated by the Peruvian Ministry of Economy and Finance using expenditure surveys from the Peruvian Institute of Statistics. 
Table 3 shows loss rates by the contents of the envelope and the sender's last name. Again, envelopes with money were more likely to be lost than those without money, whether or not the sender's last name was foreign or a family name. The difference between money and no money envelopes for envelopes with a foreign sender is not significantly larger, but the almost 10 percentage point difference for envelopes with a family last name is (one-sided $\mathrm{p}$-value $=0.023)$. Indeed, most loss happened for envelopes with money sent by a family member. Almost one in four of those envelopes never arrived.

Across low, middle and high-income neighborhoods, mail is lost at different rates. Table 4 shows residents in middle-income neighborhoods lose mail at the highest rate, $20.4 \%$, and those in high-income neighborhoods lose mail at the lowest rate, $13.5 \%$. The loss rate in middle-income income neighborhoods is significantly larger than in high-income neighborhoods. ${ }^{10}$

One might wonder if mail loss can be attributed to the Peruvian mail service or to the U.S. Postal Service. The results in Table 4 suggest that lost mail is happening on the Peruvian side. While it may be reasonable to think that envelopes with money might be lost on the U.S. side, it is highly unlikely that the significantly different loss rates we see across middle and high-income neighborhoods is due to the U.S. Postal Service. Such loss rates cannot exist without knowledge of neighborhoods in Lima. The next section provides further evidence of this.

Looking at the contents of the envelopes, mail with money is significantly more likely to be lost than without money in middle-income neighborhoods. In middle-income neighborhoods the loss rate of envelopes with money is over 10 percentage points larger than for envelopes without money. The loss rate in poor neighborhoods is around $18 \%$ and is similar for envelopes with and without money. High-income neighborhoods have an almost 7 percentage point increase for envelopes with money, but this is not significantly different.

\footnotetext{
${ }^{10}$ One-sided t-tests yield p-values of 0.098 comparing low to high-income loss rates and 0.045 comparing middle to high-income loss rates.
} 
This pattern of loss is consistent with an expectation that the poor are not sending valuables by mail, so loss rates are no different with and without money. The loss rates in poor neighborhoods seem to be more a reflection of poor service, rather than crime. Loss rates in middle-income and highincome neighborhoods, however, are consistent with the expectation that these populations have valuable items to send through the mail. Search is relatively larger in middle-income neighborhoods, and this may reflect an expectation that people in middle-income neighborhoods have few alternatives for sending mail.

The pattern of loss across neighborhoods is primarily driven by envelopes where the sender and recipient share the same last name. This result is important because it suggests that those handling the mail attribute a similar probability of being caught across neighborhoods when disposing of mail sent by non-family members. It also suggests that mail from a family member is given special attention since loss rates vary across neighborhoods.

Across the gender of the recipient, women suffer larger losses in poor neighborhoods and men suffer larger losses in rich neighborhoods. The loss rate for women in poor neighborhoods is higher than that for men, and the loss rate for men in high-income neighborhoods is higher than that for women. It is important to note that there are more women in poor neighborhoods than men and more men in high income neighborhoods than women. Those handling the mail may perceive that mishandling women's mail in poor neighborhoods carries less risk of complaints.

\subsection{Evidence of Strategic Crime}

The main findings show that mail with money is lost more frequently and that crime is not distributed equally across the population. The mechanism for loss seems to be that envelopes coming from family members are scrutinized more closely than those from a foreigner. In this section, we look more closely at the patterns of loss and why they might exist. 
Table 5 shows the joint effect of income and money on crime. For men, there is a level increase in loss across all neighborhoods when there is money in the envelope. For women, money does not have an effect, but neighborhood income does, with worse service in low-income neighborhoods.

The numbers in the table also allow us to calculate a difference-in-difference estimate of the effect of income on crime using our treatments variables. The presence of money in envelopes sent by a family member increases the rate of mail lost by 16.1 percentage points $(30.9 \%-14.8 \%)$ in middle-income neighborhoods and decreases it by 1.4 percentage points $(18.2 \%-19.6 \%)$ in poor neighborhoods. In other words, people are 17.5 percentage points more likely to keep envelopes sent to middle-income neighborhoods when there is suspicion of valuable content. A comparison of the richer neighborhoods and poorer neighborhoods gives a similar estimate (15.0). This increase in the likelihood of loss from poor to middle and poor to rich neighborhoods could be due to expectations that something of value might be sent in the mail or the perceived larger risk of being caught.

The results in Table 6 show that both expectations that the envelope contains something of value and the probability of being caught, which varies by the socioeconomic level of the neighborhood, explain loss rates. The last four columns in the table present results from a fixed-effects logit regression of loss on whether the envelope contained money, it was sent by a family member and interactions with neighborhood income (percent classified as poor) and whether the recipient is male. The dependent variable equals 1 if the mail did not arrive at its destination and 0 otherwise. ${ }^{11}$

The third and fourth columns show results for the subsamples of mail sent by a family member and by a foreigner. By looking only at envelopes from family members or from foreigners, we attempt to keep constant the expected cost of committing a crime, so that we can focus on expectations that the

\footnotetext{
${ }^{11}$ The same results hold with a fixed-effects linear probability model.
} 
envelope contains something of value. ${ }^{12}$ We see that the effect of money for envelopes coming from family members, controlling for the gender of the recipient and recipient fixed effects, is stronger as neighborhoods become wealthier. There is no significant effect of envelopes coming from foreigners. This confirms the results in Table 5 and suggests that expectations matter. This is so because we expect not only that both the rich and the poor care about receiving mail but that the cost of being caught stealing should not decrease with the wealth of the neighborhood. The fact that envelopes with money are lost at a higher rate as neighborhood income goes up says people seem to expect mail to contain something of value when sent to wealthier neighborhoods.

The results in the fifth and sixth columns of the regression on money and non-money envelopes are also indicative of incentives. The previous regression on family envelopes suggests that people perceive family envelopes from richer neighborhoods to contain valuables. So, we would expect that the effect of family on money envelopes to be stronger in richer neighborhoods, not weaker. The fact that we do not find this suggests that there is a counteracting force limiting the incentive to commit a crime. Since larger expected costs of being caught reduce the incentives to steal, this result is consistent with the belief that the probability of being caught stealing is larger in richer neighborhoods.

All together, these results suggest that there is an expectation of valuables sent through the mail as neighborhood income rises and this interacts with an increasing probability of being caught. This gives us a nonlinear effect of

\footnotetext{
${ }^{12}$ This is a difference-in-difference estimate on the net benefit (expectation of something of value less the expected cost of being caught) of an envelope with and without money across neighborhoods. Or, re-written, this is the net expectation of encountering something of value less the net cost of being caught taking something of value. By splitting the sample into envelopes from family members and from foreigners, we can control for the net cost of being caught across neighborhoods. We expect this to be constant, since otherwise this would say that the rich care less about receiving mail with money. So, any significant effect on money or money interacted with neighborhood will be due to expectations.
} 
neighborhood income on loss rates and a higher level of loss in middle-income neighborhoods.

\section{Robustness Checks}

This section presents regression analysis of mail loss rates to test the robustness of the results to omitted variables and specification assumptions. We check that our main results are not due to recipient-level fixed effects, our definition of neighborhood grouping by income, correlation between neighborhood income and the way mail is processed, misreporting, or other socioeconomic variables. Table 7 presents logit regression marginal effects for a dummy variable that equals 1 if the mail did not arrive at its destination and 0 otherwise. Each regression presents the effect of covariates on different subpopulations. ${ }^{13}$

The second column in Table 7 and the second column in Table 6 confirm our first basic result. Envelopes containing money are more likely to get lost. The results in Table 6 confirm that this holds with recipient-level fixed effects, and the results in Table 7 confirm it holds as does the nonlinear relationship with neighborhood income (percent classified as poor). This latter result still holds even controlling for the manner in which mail is processed across neighborhoods. The results are intuitive. Mail sent to neighborhoods with an administrative center might be lost more frequently because there are many more employees handling the mail and this helps to dissipate responsibility. Neighborhoods with more post office branches might lose less mail because it is easier to identify responsibility.

In Table 7, columns three and four show that the effect of neighborhood income is stronger for the envelopes with money. The regressions dividing the population receiving envelopes from family and non-family members confirm that it is the envelopes with money coming from family members that are more likely to get lost. The last two columns show that men are more likely

\footnotetext{
${ }^{13}$ The results are robust to autocorrelation and other specifications.
} 
to be targeted if envelopes contain money. Finally, note that the patterns of lost mail do not seem to respond to the proximity of post offices. The number of minutes it takes to get to the closest post office is not significant. ${ }^{14}$ This is important because it suggests our results are not due to lack of manpower.

The results reported above also eliminate two alternative explanation for higher loss of envelopes with money: systematic misreporting by individuals and misreporting envelopes with money. First, since the results hold when controlling for recipient fixed effects, individual misreporting is not causing the differential loss with money. Second, since the recipients did not know ahead of time what kind of envelope was sent, there is no reason to believe that the money effect is due to people not paying attention to the money envelopes. Also, they could keep the money and therefore did not need to say it was lost. Finally, the nonlinear effect of income on loss rates, especially for envelopes with money, is not what one would expect if there was differential shirking by income. People in richer neighborhoods might care less about the job and therefore shirk more, but that would imply more lost mail in richer neighborhoods, not less.

The results in Table 7 are also robust to learning and the inclusion of other socio-economic information, such as family size, time in residence and marital status. Envelopes with money are more likely to be lost and neighborhood income is nonlinearly related to loss rates. ${ }^{15}$ Also, the fact that money envelopes are more likely to be lost, even when controlling for recipient fixed effects, is strong evidence that this result is robust.

One final alternative explanation for our results on mail loss is that loss is happening because household members are taking the envelopes, not the mail service. This does not seem to be the case. In households where the

\footnotetext{
${ }^{14}$ The number of minutes to the closest post office is based on an accessibility model which calculates the least cost path surface (based on time) from any place, using GIS. The accessibility measure uses three different levels of roads with different speeds of movement.

${ }^{15}$ Learning is tested by the inclusion of a lagged term for loss or a dummy variable that equals one if the first envelope did not arrive. Our main results still hold.
} 
recipient is a man, the more members in the household, the less likely the mail is lost. This is not consistent with internal household crime.

\section{Conclusions}

Using a simple and novel field experiment that allows for crime, we examine strategic behavior in the mail sector in Lima, Peru. We hypothesize that the very nature of mail delivery gives an opportunity to those who handle the mail to "lose" mail if it is beneficial to do so. Our design allows us to differentiate poor service from targeted crime and to investigate what information is pertinent in crime and who suffers the most from it.

We have several key findings. First, loss rates are very high. Over $18 \%$ of all mail sent never arrived at its destination. These losses are huge and present large barriers for the development of efficient commerce. Second, this high loss rate is partially explained by poor service but not completely. Envelopes containing money were $50 \%$ more likely to be lost than those without money. So, mail loss is not random and hints at strategic behavior. Third, when the sender's last name matched the recipient's last name, the mail was almost twice as likely to be lost if it contained money. Clearly, those who handle the mail are looking for clues that might suggest that an envelope holds something of value. Fourth, middle-income neighborhoods suffer the highest loss rates and high-income neighborhoods suffer the lowest. This result (and the previous) lends support for the crime occurring in Peru rather than the U.S. since it would require the U.S. Postal Service to know which neighborhoods were rich or poor.

Finally, the patterns of crime we observe are consistent with expectations that the recipient could receive something of value and the perceived probability of being caught stealing. This results in a nonlinear effect of neighborhood income on loss. Looking only at mail from family members, we see that loss increases as neighborhood income rises if the mail contains money, suggesting that there is an expectation that residents in middle-income and 
wealthy neighborhoods may have something valuable to steal. The magnitude of loss is higher in middle-income neighborhoods though, supporting the notion that the probability of being caught is more likely in wealthy neighborhoods. So, we see the highest loss rates in middle-income neighborhoods when there is a hint that the envelope contains something of value.

Put together our results suggest a model of crime where those who handle the mail are looking for items of value to steal. Moreover, crime is not independent of the neighborhood's characteristics.

While our study cannot speak to the presence of large inefficiencies in all the sectors dealing with the transaction of goods and services, it highlights the large barriers to market development that developing economies face. Our study further shows that private firms providing public services face incentives problems due to moral hazard in the same way the government does. The nature of the good seems to be as important as the nature of ownership. The sophistication in criminal activity found in our study suggests that inexpensive, reliable alternatives and affordable monitoring might be difficult to obtain. Incentive problems can prevent market development as much as inefficiencies in governance and lack of competition do. 


\section{References}

Armantier, Olivier and Amadou Boly (2008), "Can Corruption Be Studied in the Lab? Comparing a Field and a Lab Experiment," Working Paper, Federal Reserve Bank of New York.

Becker, Gary (1968), "Crime and Punishment: An Economic Approach," Journal of Political Economy, 76, 169-217.

Becker, Gary and George J. Stigler (1976), "Law Enforcement, Malfeasance and the Compensation of Enforcers" Journal of Legal Studies, 3, 1-18.

Bertrand, Marianne, Simeon Djankov, Rema Hanna, Sendhil Mullainathan (2007), "Obtaining a Driving License in India: An Experimental Approach to Studying Corruption," Quarterly Journal of Economics, 122(4), 1639-1676.

Di Tella, Rafael and Ernesto Schargrodsky (2003) "The Role of Wages and Auditing during a Crackdown on Corruption in the City of Buenos Aires," Journal of Law and Economics, 46(1), 269-92.

Di Tella, Rafael and Ernesto Schargrodsky (2004) "Do Police Reduce Crime? Estimates Using the Allocation of Police Forces after a Terrorist Attack," American Economic Review, 94(1), 115-33.

Duggan, Mark and Steven Levitt (2002) "Winning Isn't Everything: Corruption in Sumo Wrestling," American Economic Review, 92(5), 1594-1605.

Erlich, I. (1973) "Participation in Illegitimate Activities: A Theoretical and Empirical Investigation," Journal of Political Economy, 81, 521-565.

Fisman, R. and E. Miguel, (2007) "Corruption, Norms, and Legal Enforcement: Evidence from Diplomatic Parking Tickets," Journal of Political Economy, 115, 1020-1048.

Glaeser, Edward L., Sacerdote, Bruce, and Scheinkman, Jose' A. (1996) "Crime and Social Interactions." Quarterly Journal of Economics, 111, 50748.

Hunt, Jennifer and Sonia Laszlo (2008), "Is Bribery Really Regressive? Bribery's Costs, Benefits and Mechanisms," Working paper, McGill University. 
Jacob, B. and L. Lefgren (2003) "Are Idle Hands the Devil's Workshop? Incapacitation, Concentration, and Juvenile Crime," American Economic Review, 93, 1560-1577.

Levitt, Steven (1997), "Using Electoral Cycles in Police Hiring to Estimate the Effect of Police on Crime," American Economic Review, 87(3), 270-290.

Olken, Benjamin (2007) "Monitoring Corruption: Evidence from a Field Experiment in Indonesia," Journal of Political Economy, 115(2), 200-249.

Reinikka, Ritva, and Jakob Svensson (2005) "Fighting Corruption to Improve Schooling: Evidence from a Newspaper Campaign in Uganda." Journal of the European Economic Association, 3, 259-267.

Reinikka, Ritva and Jakob Svensson (2004) "Local Capture:Evidence from a Central Government Transfer Program in Uganda," Quarterly Journal of Economics, 119, 679-05.

World Bank (2009), "World Development Report 2009: Reshaping Economic Geography," World Development Report, World Bank. 


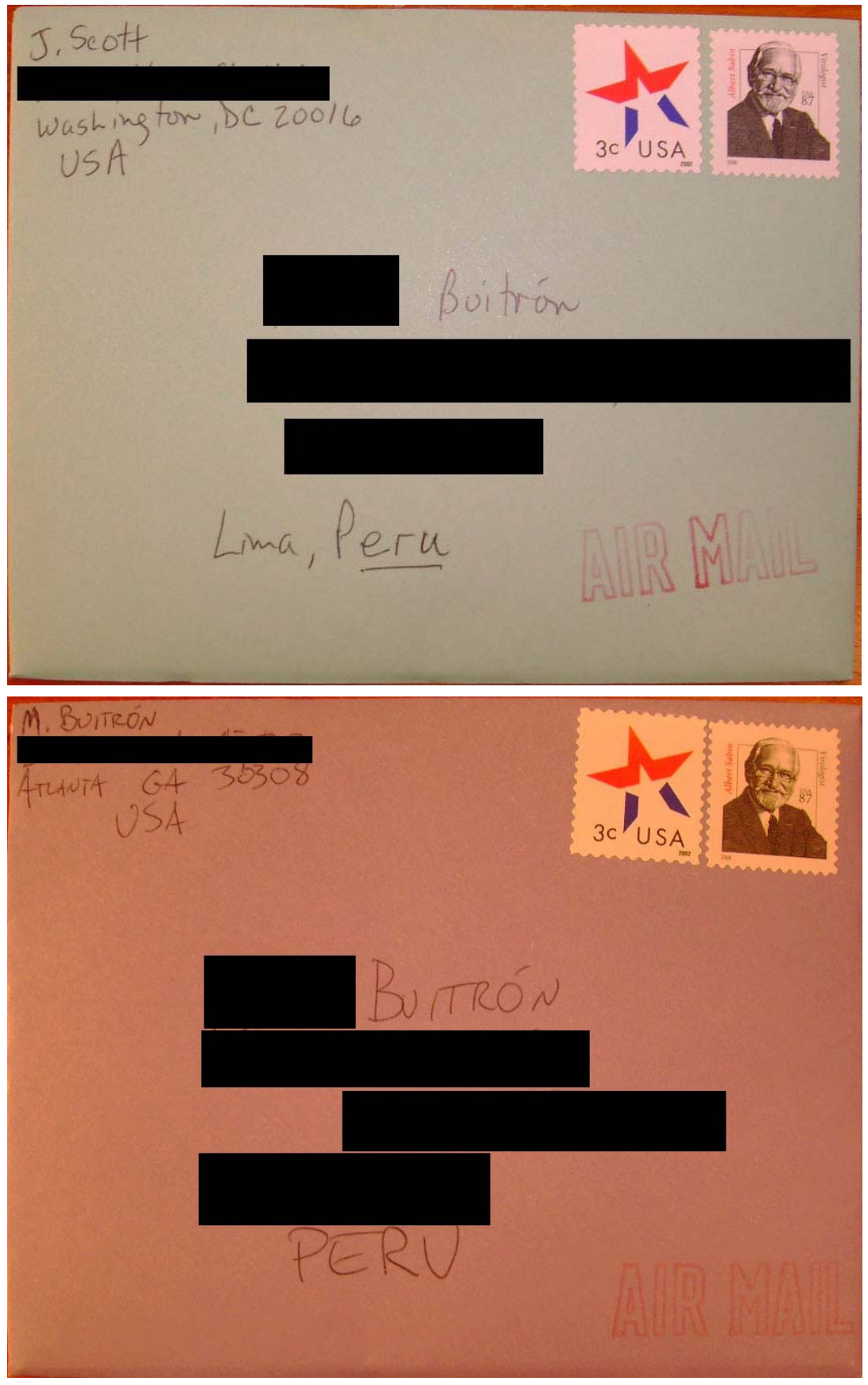

Figure 1. Examples of Envelopes Sent

(To preserve confidentiality, addresses and first names are blocked) 


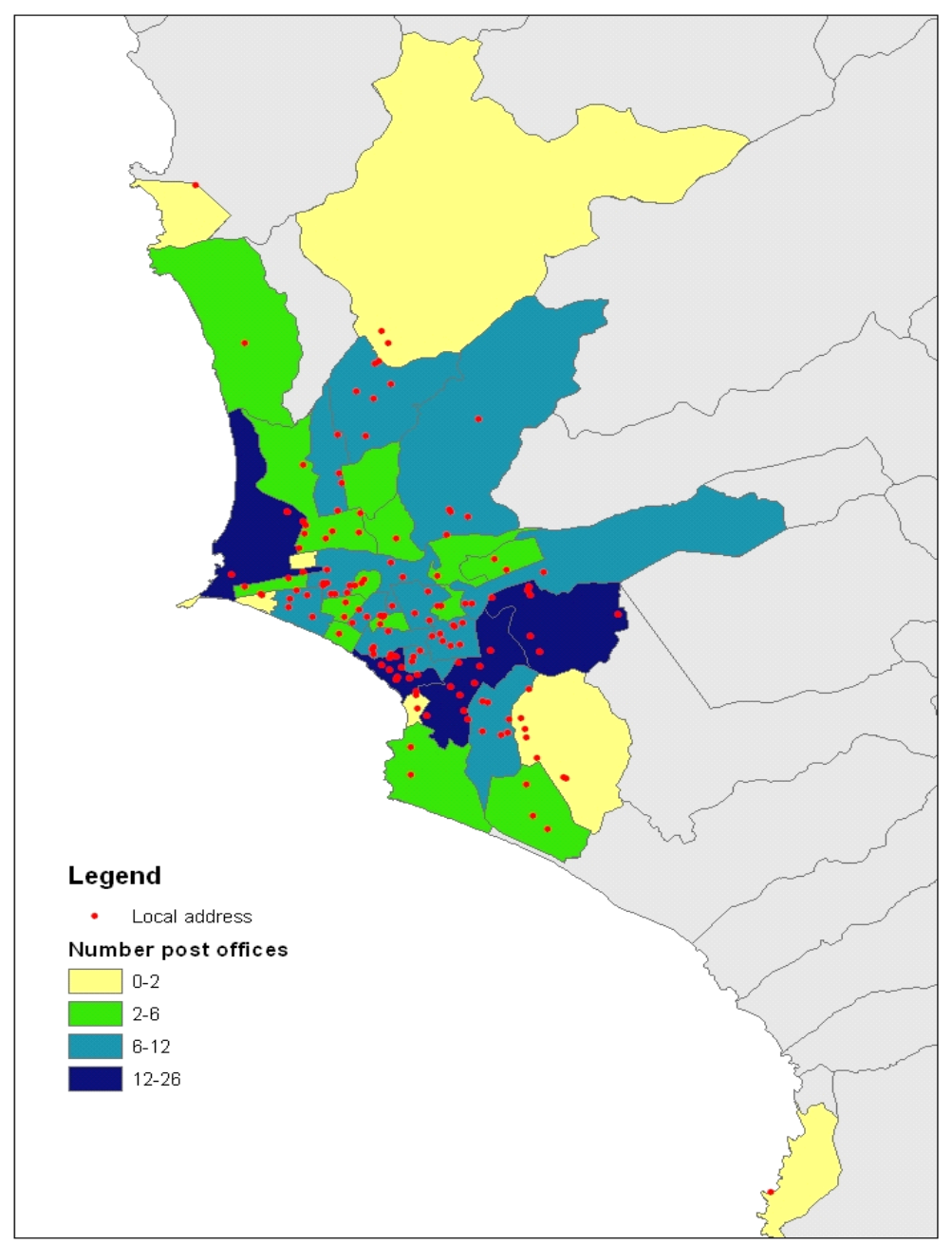

Figure 2: Distribution of Addresses Across Lima, Peru 
Table 1

Experimental Design

\begin{tabular}{lll}
\hline & \multicolumn{2}{l}{ Contents of Envelope } \\
Sender Last Name & Money & No Money \\
\hline Foreign & $\mathrm{n}=136$ & $\mathrm{n}=131$ \\
Family & $\mathrm{n}=135$ & $\mathrm{n}=139$ \\
\hline
\end{tabular}

Table 2

Descriptive Statistics of Sample Recipients

\begin{tabular}{llll}
\hline & Percent & Std Dev & \# Obs \\
\hline Male Recipients & 47.5 & & 141 \\
Low Income & 34.8 & & 49 \\
Middle Income & 39.7 & & 56 \\
High Income & 25.5 & & 36 \\
Age (mean, years) & 37.2 & 10.1 & 124 \\
University Education & 57.4 & & 136 \\
Married or Cohabitating & 44.1 & & 136 \\
Family size (mean, number) & 4.1 & 1.5 & 124 \\
Family in U.S. & 47.1 & & 136 \\
Time in Residence (mean, years) & 16.5 & 12.8 & 124 \\
Minutes to Post Office (mean) & 3.0 & 8.4 & 140 \\
\hline Note: some variables have missing values because of survey non-response. \\
\hline
\end{tabular}


Table 3

Loss Rates

(in percent)

Overall and by Contents

\begin{tabular}{lcc}
\hline & & Number \\
\hline Overall & 18.1 & 98 \\
Money & 21.4 & 58 \\
No Money & 14.8 & 40 \\
\hline
\end{tabular}

\begin{tabular}{lcc}
\multicolumn{3}{c}{ Experimental Treatments } \\
\hline & $\begin{array}{c}\text { Contents of Envelope } \\
\text { Money }\end{array}$ & No Money \\
\hline Foreign & 19.8 & 16.0 \\
Family & 23.0 & 13.7 \\
\hline
\end{tabular}

\section{Table 4}

Loss Rates by Income Groups (in percent)

\begin{tabular}{lccc}
\hline & Low Income & Middle Income & High Income \\
\hline Overall & 18.9 & 20.4 & 13.5 \\
Money & 19.8 & 25.7 & 16.9 \\
No Money & 18.0 & 15.3 & 10.0 \\
& & & \\
Foreign Sender Name & 18.9 & 18.3 & 16.4 \\
Family Sender Name & 18.9 & 22.4 & 10.3 \\
& & & \\
Male Recipient & 14.3 & 20.0 & 20.4 \\
Female Recipient & 21.8 & 20.8 & 1.9 \\
\hline
\end{tabular}


Table 5

Loss Rates

by Money and Income Groups (in percent)

Envelope with Money

Low Income Middle Income High Income

\begin{tabular}{lccc}
\hline Foreign Sender Name & 21.3 & 20.4 & 17.1 \\
Family Sender Name & 18.2 & 30.9 & 16.7 \\
& & & \\
Male Recipient & 17.1 & 28.0 & 25.0 \\
Female Recipient & 21.4 & 23.7 & 3.7 \\
\hline
\end{tabular}

Envelopes with No Money

Low Income Middle Income High Income

\begin{tabular}{lccc}
\hline Foreign Sender Name & 16.3 & 16.0 & 15.8 \\
Family Sender Name & 19.6 & 14.8 & 3.1 \\
& & & \\
Male Recipient & 11.4 & 12.0 & 15.9 \\
Female Recipient & 22.2 & 18.0 & 0.0 \\
\hline
\end{tabular}


Table 6

Probability of Mail Loss

Logit Fixed-Effects Regressions

\begin{tabular}{llllll}
\hline & All & Family & Foreign & Money & No Money \\
\hline Money & $0.606^{* *}$ & $2.687^{* *}$ & -0.106 & & \\
& $(0.029)$ & $(0.034)$ & $(0.919)$ & & \\
Family & 0.025 & & & 1.250 & -0.922 \\
& $(0.928)$ & & & $(0.259)$ & $(0.424)$ \\
Money*Percent Poor & & $-0.079^{* *}$ & -0.008 & & \\
& & $(0.027)$ & $(0.790)$ & & \\
Money*Man & & 1.117 & 0.817 & & \\
Family*Percent Poor & & $(0.272)$ & $(0.367)$ & & \\
& & & & -0.021 & 0.036 \\
Family*Man & & & & $(0.500)$ & $(0.258)$ \\
& & & & -0.663 & -0.387 \\
Individual Fixed Effects & yes & yes & yes & $(0.476)$ & $(0.682)$ \\
N & 541 & 274 & 267 & 271 & 270 \\
Log likelihood & -71.96 & -15.23 & -15.32 & -14.47 & -15.52 \\
\hline
\end{tabular}

Note: p-value in parentheses. ${ }^{*}$ p-value $<0.10,{ }^{* *}$ p-value $<0.05,{ }^{* * *}$ p-value $<0.01$.

Variables: Money=1 if envelope contained money, Family=1 if sender's last name was the same as recipient's, $\mathrm{Man}=1$ if recipient was a man, Percent Poor=percent of population in neighborhood living in poverty. 
Table 7

Probability of Mail Loss

Logit Regressions - Marginal Effects

\begin{tabular}{lccccccc} 
& All & Money & No Money & Family & Foreign & Man & Woman \\
\hline Money & $0.063^{*}$ & & & $0.099^{* *}$ & 0.026 & $0.118^{* *}$ & 0.016 \\
& $(0.058)$ & & & $(0.040)$ & $(0.570)$ & $(0.017)$ & $(0.707)$ \\
Family & 0.005 & 0.031 & -0.020 & & & -0.022 & 0.027 \\
Man & $(0.868)$ & $(0.516)$ & $(0.621)$ & & & $(0.632)$ & $(0.516)$ \\
& 0.030 & 0.080 & -0.017 & -0.004 & 0.067 & & \\
Percent Poor & $(0.354)$ & $(0.110)$ & $(0.678)$ & $(0.930)$ & $(0.145)$ & & \\
& $0.012^{* *}$ & $0.015^{*}$ & 0.010 & $0.013^{*}$ & 0.012 & 0.013 & $0.025^{* * *}$ \\
Percent Poor & $(0.023)$ & $(0.063)$ & $(0.155)$ & $(0.083)$ & $(0.101)$ & $(0.100)$ & $(0.004)$ \\
Squared & $-0.000^{* *}$ & $-0.000^{*}$ & -0.000 & -0.000 & -0.000 & $-0.000^{*}$ & $-0.000^{* *}$ \\
Minutes to & $(0.045)$ & $(0.065)$ & $(0.299)$ & $(0.152)$ & $(0.122)$ & $(0.076)$ & $(0.013)$ \\
Post Office & 0.002 & 0.004 & -0.001 & -0.000 & 0.003 & 0.009 & 0.001 \\
Administrative & $(0.428)$ & $(0.129)$ & $(0.687)$ & $(0.941)$ & $(0.201)$ & $(0.340)$ & $(0.720)$ \\
Center & $0.119^{* * *}$ & $0.144^{* *}$ & $0.092^{*}$ & 0.076 & $0.168^{* * *}$ & $0.145^{* *}$ & 0.075 \\
Number of Post & $(0.001)$ & $(0.010)$ & $(0.054)$ & $(0.141)$ & $(0.002)$ & $(0.012)$ & $(0.126)$ \\
$\quad$ Office Branches & $\left(0.028^{* *}\right.$ & -0.021 & $-0.033^{* *}$ & $-0.033^{* *}$ & -0.021 & $-0.040^{* *}$ & $-0.031^{* *}$ \\
Mailing number & 0.002 & $(0.225)$ & $(0.026)$ & $(0.046)$ & $(0.180)$ & $(0.044)$ & $(0.023)$ \\
$\quad(1-4)$ & $(0.920)$ & $(0.910)$ & $(0.777)$ & $(0.581)$ & $(0.590)$ & $(0.442)$ & $(0.540)$ \\
& & & & & & & \\
N & 537 & 269 & 268 & 272 & 265 & 258 & 279 \\
Log Likelihood & -239.57 & -130.78 & -106.02 & -122.49 & -114.52 & -115.57 & -117.28 \\
& & & & & & & \\
\hline
\end{tabular}

Note: p-value in parentheses. ${ }^{*}$ p-value $<0.10,{ }^{* *}$ p-value $<0.05,{ }^{* * *}$-value $<0.01$.

Variables: Money=1 if envelope contained money, Family=1 if sender's last name was the same as recipient's, Man=1 if recipient was a man, Percent Poor=percent of population in neighborhood living in poverty, Minutes to post office $=$ number of minutes from residence to closest post office, Mailing number $=1$ if first mailing, $=2$ if second mailing, etc., Administrative Center $=1$ if an administrative center is located in neighborhood, Number of Post Office Branches=number of branches in neighborhood. 